\title{
Interfacial Actions and Adherence of an Interpenetrating Polymer Network Thin Film on Aluminum Substrate
}

\author{
Weiwei Cui ${ }^{1,2}$, Dongyan Tang,*, Jie Liu ${ }^{1}$, Fan Yang ${ }^{1}$ \\ ${ }^{1}$ Department of Chemistry, Harbin Institute of Technology, Harbin, China; ${ }^{2}$ College of Materials Science and Engineering, Harbin \\ University of Science and Technology, Harbin, China. \\ Email: *dytang@hit.edu.cn
}

Received August $9^{\text {th }}, 2011$; revised September $13^{\text {th }}, 2011$; accepted September $25^{\text {th }}, 2011$.

\begin{abstract}
The interpenetrating polymer networks (IPN) thin film with the $-C=O$ group in one network and the terminal $-N=C=O$ group in another network on an aluminum substrate to reinforce the adherence between IPN and aluminum through interfacial reactions, were obtained by dip-pulling the pretreated aluminum substrate into the viscous-controlled IPN precursors and by the following thinning treatment to the IPN film to a suitable thickness. The interfacial actions and the adhesion strengths of the IPN on the pretreated aluminum substrate were investigated by the X-ray photoelectron spectroscopy (XPS), Fourier transform infrared spectroscopy $(F T I R)$ and strain-stress $(\sigma-\varepsilon)$ measurements. The XPS and FTIR detection results indicated that the elements' contents of $N, O$, and Al varied from the depths of IPN. The interfacial reaction occurred between the $-N=C=O$ group of IPN and the $A l O(O H)$ of pretreated aluminum. The increased force constant for $-C=O$ double bond and the lower frequency shift of $-C=O$ stretching vibration absorption peak both verified the formation of hydrogen bond between the $-\mathrm{OH}$ group in $\mathrm{AlO}(\mathrm{OH})$ and the $-\mathrm{C}=\mathrm{O}$ group in IPN. The adherence detections indicated that the larger amount of $-N=C=O$ group in the IPN, the higher shear strengths between the IPN thin film and the aluminum substrate.
\end{abstract}

Keywords: Interfacial Action, Adherence, Interpenetrating Polymer Network (IPN), Aluminum, Thin Film

\section{Introduction}

Adsorption of polymer onto the surface of metal is of great importance in such applications as the adhesive bonding, corrosion protection, colloid stabilization and many other areas $[1,2]$. But the weak linkage between the two different materials affects the composites' stability, and therefore restricts their long-term applications $[3,4]$. Reinforcing the interfacial adhesion between metal and polymer is of worldwide scientific and technical significance $[5,6]$.

In recent years, the role of polymers containing nitrogen- or oxygen-functionalities in polymer-metal adhesion has been an important subject [7,8]. It has been reported that the adhesion strength between polymer and metal could be enhanced significantly by the incorporation of nitrogen- or oxygen-containing functionalities into polymer [9-11]. This illustrates that the reactions between polymer and metal can improve the adhesion effectively.
However, there usually exist the complex structures for polymer, the determination of the polymer reaction sites with metals facilitates the choice of metal/polymer systems, especially when specific properties such as interfacial stability and adhesion are required $[12,13]$.

\section{Experimental}

\subsection{Pretreatment of Aluminum Substrate}

Aluminum substrate $(1.5 \mathrm{~cm} \times 2 \mathrm{~cm})$ were obtained by cutting, wiping the aluminum sheet with acetone, drying and then immersing in boiling deionized water for $3 \mathrm{~min}$. After removal from the water, the sheet was allowed to dry under ambient conditions for $10 \mathrm{~min}$ before further treatment [14]. Then it was dipped into the dichromate salt/concentrated sulfuric acid lotion for $0.5 \mathrm{~min}-2 \mathrm{~min}$, rinsed with deionized water and sodium carbonate solution for 10min. After that, it was rinsed again with large amount of deionized water, scrubbed with acetone and 
put into the boiled water for $3 \mathrm{~min}$, then dried in air.

\subsection{Preparation of an IPN Thin Film on an Aluminum Substrate}

The pretreated aluminum substrate was dipped into the IPN precursors (with fixed mass ratio $(1: 1)$ of cross linker (trimethylolpropane) to chain expander (1,4-butylene glycol), both were dehydrated at $110^{\circ} \mathrm{C}$ for 4 hours before use), fixed mass rate (100:2:1) of vinyl ester resin to initiator (benzoyl peroxide) and catalyzer (cobalt naphthenate), and variable mol ratio of prepolymer (-NCO) to curing agent $(-\mathrm{OH})$ ). Through controlling the viscous of precursors and the lifting speed of the aluminum substrate into the precursors, the IPN thin film on the aluminum substrate(represent as IPN-Al) can be obtained. Then the IPN-Al was place into a heat oven at $80^{\circ} \mathrm{C}$ for 1 hour. After that, it was immersed into ethyl acetate for $30 \mathrm{~min}$ and then scrubbed with acetone to the required thickness.

\subsection{The Viscous Determination and the Morphology Observation}

The viscous of IPN precursors were determined by a NDJ1 rotational viscometer (Shanghai Optical Apparatus Co., $\mathrm{CN}$ ). The thickness of IPN thin film was measured by a HG-1060 thickness gauge (Peijing Measuring \& Cutting Tool Co. CN). The surface micro morphologies of the aluminum substrate (before and after treatment) were detected by a XSZ-H metallographic microscope (Nippon Electric Co., JP).

\subsection{The Interfacial Actions Detection and the Adhesion Strengths Measurements}

The surface elemental compositions of the IPN and the aluminum substrate were determined by a PHI 5700 ESCA XPS systems (Physical Electronics, USA) employing an $\mathrm{Al} \mathrm{K} \alpha \mathrm{X}$-ray source (energy is $1486.6^{\circ} \mathrm{eV}$ ) and a precise hemispherical electronic energy analyzer. The transfer energy mode was fixed at $12.5 \mathrm{kV}$ and $250 \mathrm{~W}$ with an operating chamber pressure of approximately $10^{-6}$ Torr. The survey spectrum was recorded at a constant energy of $187.8 \mathrm{eV}$. The instrumental error in terms of the binding energy was within $\pm 0.1 \mathrm{eV}$. Data were recorded at different incident angles after neutralization of the charges. The existence of groups and their interaction types or sites of the IPN-Al interface were detected by an AVATAR 360 infrared spectrometer (Nicolet Co. USA) with the solution values of $4 \mathrm{~cm}^{-1}$ and an incident angle of $22^{\circ}$. The adhesion strength tests were preceded by applying the IPN precursors onto the edge of an aluminum substrate and then overlapping by another aluminum substrate onto the precursors. The lap area would be 20 $\mathrm{mm}$ in width and $12.5 \pm 0.5 \mathrm{~mm}$ in length. This assembly was tightly clamped under $1 \mathrm{MPa}$. The adhesion strength was measured by a Z050 electrical universal tester (Zwick Co. DN) according to the GB7124-1986 standard method at a pull rate of $5 \mathrm{~mm} / \mathrm{min}$. The lap shear strength was calculated by dividing the strength by the lap area. Three sets of samples for each variable component ratios of the IPN were tested, and the average was reported as the lap shear strength.

\section{Results and Discussion}

\subsection{The Micro Morphologies of the Pretreated Aluminum Substrate Surface}

The observation of the aluminum substrate (before and after treatment) with the 100 times magnification coefficient by the metallographic microscope was given in Figure 1.

As shown in Figure 1, the flat surface of the aluminum with metal textures and metal shines(a) was changed into a coarse and porous surface(b) after treatment.

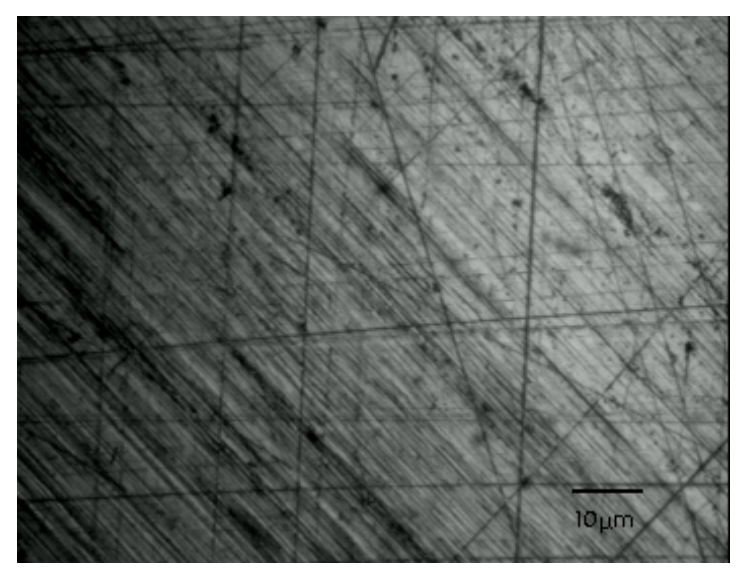

(a)

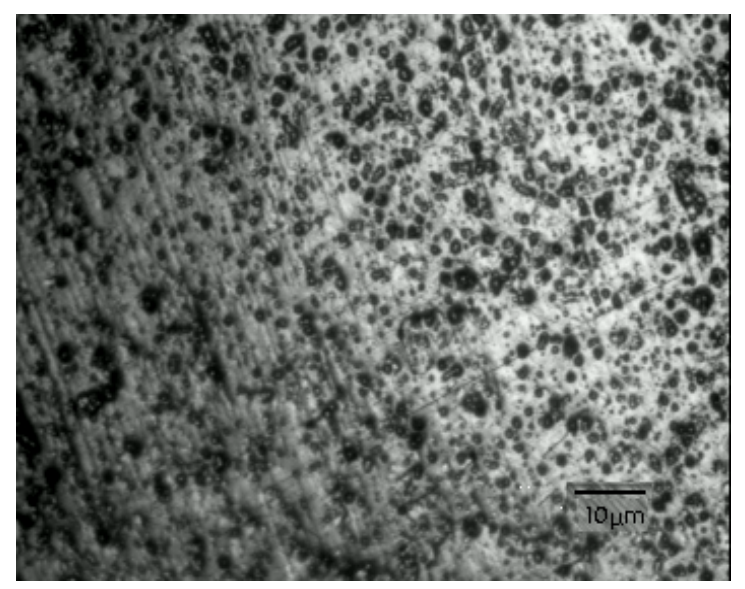

(b)

Figure 1. The metallographic microscope photos; (100 times magnification) of aluminum; (before treatment (a) and after treatment(b)). 
Since the actual surface area $\left(a^{\prime}\right)$ after treatment became larger than the original surface $\operatorname{area}(a)$ for the aluminum, so the roughness factor $(\varphi$, which equals to $a$ ' $a$ ) was larger or equal to 1 . According to the literature [15], the roughness factor also equals to the product of $\cos \theta(\theta$ refers to the contact angle of the IPN precursors onto the original aluminum) with the surface tension of liquid ( $\gamma_{l v}$, which equals to the minus of the surface tension of solid to the interface tension of liquid-solid). Since $\cos \theta^{\prime} \geq$ $\cos \theta$, so the wetting ability of coarse surface ( $\Delta F i^{\prime}$ ) equals to $\varphi\left(\gamma_{s v}-\gamma_{s l}\right)$ or $\gamma_{l v} \varphi \cos \theta$. The adhesion work of the coarse surface $\left(W_{A}{ }^{\prime}\right)$ equals to $\gamma_{l v}+\varphi\left(\gamma_{s v}-\gamma_{s l}\right)$ or $\gamma_{l v}(1+$ $\varphi \cos \theta))$. While under a very well wetting condition, $\theta<$ $90^{\circ}$ and $\cos \theta>0$, so $\Delta F i '>\Delta F i$ ( $\triangle F i$, the original wetting ability) and $W_{A}{ }^{\prime}>W_{A}$ ( $W_{A}$, the original work). Thus the porous aluminum in diameters of $0.5 \mu \mathrm{m}-2 \mu \mathrm{m}$ increased the surface areas greatly and thus produced intermolecular forces and electrostatic attractions when contacted with the IPN. Further, the possibility of the formation of chemical bonds within the interface between the IPN and the aluminum increased apparently [16].

\subsection{The Relationship of the Thickness of the Thin Film with the Viscous of the IPN Precursors}

The relationship of the thickness of the IPN thin film with the viscous of the IPN precursors was shown in Figure 2. The lower viscous of the IPN precursors led to the thinner IPN film onto the aluminum substrate (which was suitable for the following interfacial reaction detections). But lower viscous meant less crosslink degree within the each network of IPN, and also meant a lower strength values between the IPN and the aluminum substrate. So in present studies, the thin film obtained by the dip-pulling method was then thinned by a following solvent extraction and acetone scrubbing.

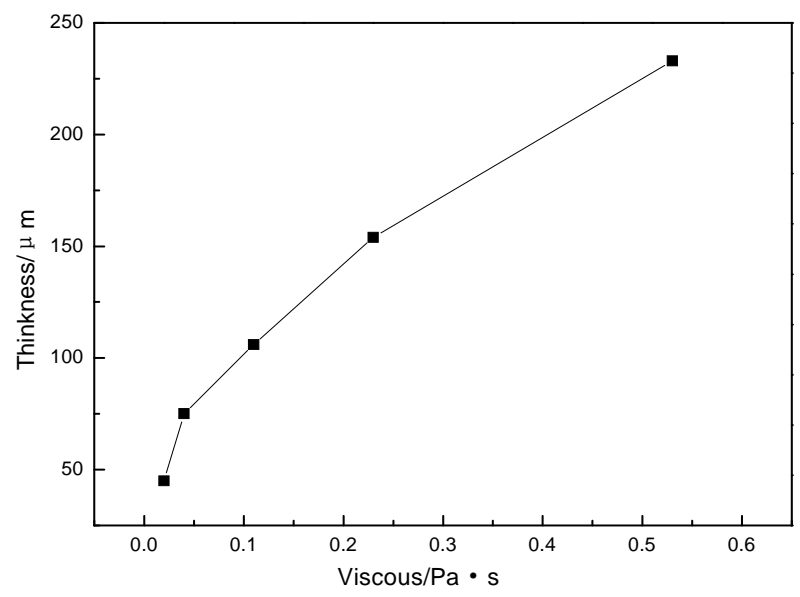

Figure 2. The relationship of the thickness of the IPN thin film with the viscous of the IPN precursors.

\subsection{The Elemental States and the Elemental Contents of the IPN-Al on the Different Depths of the Interface}

The XPS spectra of C1s at different incident angles with different depths were shown in Figure 3(the incident angles were at $45^{\circ}, 75^{\circ}$ and $90^{\circ}$, respectively) by setting $\mathrm{Al}_{2} \mathrm{O}_{3}$ with the binding energy of $73.82 \mathrm{eV}$ as the standard to neutralize the charges. The content of carbon decreased with the increase of depths from the surface of IPN to the interface of IPN-Al. And the binding energy of carbon shifted toward the higher frequencies gradually with the increase of the incident angles. These illustrated that the chemical environment of carbon at the IPN-Al interface has been changed to form the chemical bond at the higher frequency ranges.

Changes of the contents of $\mathrm{O} 、 \mathrm{C} 、 \mathrm{Al} 、 \mathrm{~N}$ at the different depths of IPN-Al interface were shown in Figure 4 by the XPS detection results at different incident angles.

If the incident angle $(\theta)$ is $90^{\circ}$, and the depth is represented as $d$, then the depth at $\theta$ is $d \sin \theta$. When $\theta$ is $90^{\circ}, d$ is approximately $10 \mathrm{~nm}$. The content of carbon decreased, whereas the content of oxygen, aluminum, and nitrogen increased with the increase of the depths. These results suggested that, the higher contents of $\mathrm{N}$ and $\mathrm{O}$ appeared at places closer to the Al substrate. Therefore, the higher reactive activities could be achieved at the interface between the nitrogen- and oxygen containing functionalities in IPN and the aluminum.

\subsection{The Interfacial Actions and the Adhesion Strengths of IPN-Al}

The comparisons of the characteristic peaks in FTIR spectra of IPN and IPN-Al were listed in Table 1. The absorption peak at $1411.71 \mathrm{~cm}^{-1}$, which assigned to the

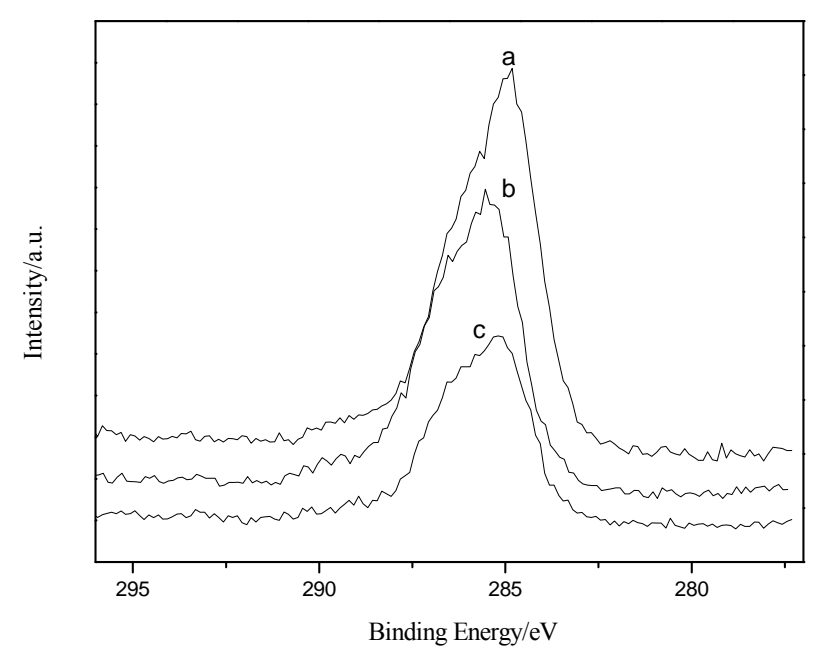

Figure 3. XPS spectra of C1s of the IPN-Al interface at different incident angles $\left(\mathrm{a}-45^{\circ} ; \mathrm{b}-75^{\circ} ; \mathrm{c}-90^{\circ}\right)$. 


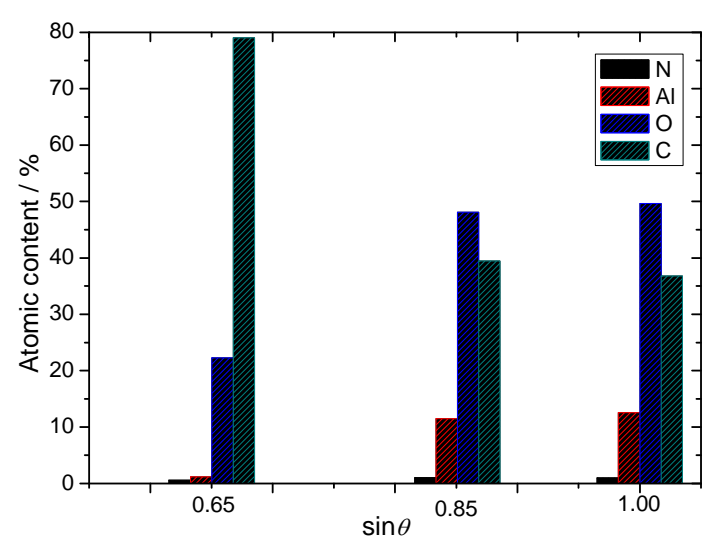

Figure 4. Relationship between the elemental contents and the incident angles of IPN-Al.

Table 1. Attribution of the characteristic absorption peaks in FTIR spectra of IPN and IPN-Al.

\begin{tabular}{ccc}
\hline $\begin{array}{c}\text { Wavenumber shiftness } \\
/ \mathrm{cm}^{-1}\end{array}$ & Intensity & $\begin{array}{c}\text { Attribution of the characteristic } \\
\text { absorption peaks }\end{array}$ \\
\hline $\begin{array}{c}1731.85 \rightarrow 1726.65 \\
(\mathrm{IPN}) \quad \text { (IPN-Al) }\end{array}$ & Strong & $\begin{array}{c}\text { Ester } \mathrm{C}=\mathrm{O} \text {, amide II bond, } \\
\mathrm{C}=\mathrm{O} \text { stretching vibration }\end{array}$ \\
$\begin{array}{c}1411.71 \rightarrow \text { none } \\
\begin{array}{c}\text { (IPN) (IPN-Al) } \\
1237.99 \rightarrow 1227.25 \\
(\mathrm{IPN}) \quad \text { (IPN-Al) }\end{array}\end{array}$ Stroak & $\begin{array}{c}\mathrm{N}=\mathrm{O} \text { symmetrical stretching } \\
\text { Vibration }\end{array}$ \\
\hline
\end{tabular}

weak symmetrical stretching vibration of $-\mathrm{N}=\mathrm{C}=\mathrm{O}$, disappeared in the spectrum of IPN-Al, verified the reaction between the little amount of $-\mathrm{N}=\mathrm{C}=\mathrm{O}$ group remained in IPN with the $\mathrm{AlO}(\mathrm{OH})$ in aluminum substrate. Since the formation of hydrogen bond could decrease the force constant for $-\mathrm{C}=\mathrm{O}$ double bond, and further produce the lower frequency shift for the $-\mathrm{C}=\mathrm{O}$ group. So the lower frequencies shift of the $-\mathrm{C}=\mathrm{O}$ stretching vibration peak from $1731.85 \mathrm{~cm}^{-1}$ for IPN to $1726.65 \mathrm{~cm}^{-1}$ for IPN-Al, the $-\mathrm{C}-\mathrm{O}$ stretching vibration peak from $1237.99 \mathrm{~cm}^{-1}$ for IPN to $1227.25 \mathrm{~cm}^{-1}$ for IPN-Al both inferred the formation of hydrogen bond between the $-\mathrm{C}=\mathrm{O}$ in IPN and the $-\mathrm{OH}$ in $\mathrm{AlO}(\mathrm{OH})$.

The comparisons of the amide II bond stretching vibration peaks in FTIR spectra were shown in Figure 5 to verify the formation of hydrogen bond by the $-\mathrm{C}=\mathrm{O}$ with the $-\mathrm{OH}$ group in $\mathrm{AlO}(\mathrm{OH})$ further.

The $-\mathrm{C}-\mathrm{N}$ stretching vibration peak at $1508.14 \mathrm{~cm}^{-1}$ in IPN was divided into two peaks in IPN-Al. The formation of hydrogen bond decrease the electronic cloud density of $-\mathrm{C}=\mathrm{O}$ to stabilize the carbon atom, so the electronic cloud density of $-\mathrm{C}-\mathrm{N}$ increased. So the increased force constant for $\mathrm{C}-\mathrm{N}$ bond further led to the higher frequency shift for $-\mathrm{C}-\mathrm{N}$ absorption peak. The $-\mathrm{C}-\mathrm{N}$ stretching vibration peak at $1517.78 \mathrm{~cm}^{-1}$ was induced by the formation of hydrogen bond. The reaction could be represented as follows:

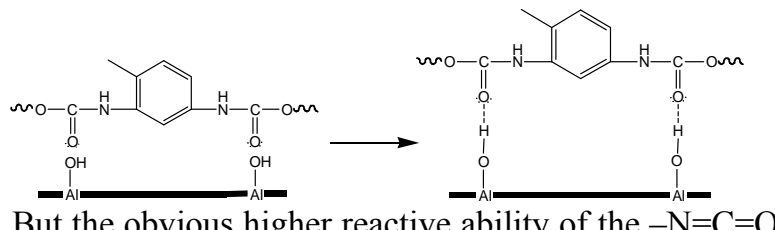

But the obvious higher reactive ability of the $-\mathrm{N}=\mathrm{C}=\mathrm{O}$ with the $\mathrm{AlO}(\mathrm{OH})$ than that $-\mathrm{C}=\mathrm{O}$ in urethane with the $\mathrm{AlO}(\mathrm{OH})$ prohibited the reaction between the $\mathrm{AlO}(\mathrm{OH})$ and the $-\mathrm{C}=\mathrm{O}$ mostly, so there only existed a weak hydrogen bond at IPN-Al interface.

The adhesion strengths between aluminum and IPN with different component ratios were shown in Figure 6 and the calculated results were listed in Table 2 .

The adhesion strengths of IPN-Al with more $-\mathrm{N}=\mathrm{C}=\mathrm{O}$ group were larger than that with less one. This indicated that the more chemical reactions between more $-\mathrm{N}=\mathrm{C}=\mathrm{O}$ group and pretreated aluminum resulted in a significant increase in adhesion strength. The reduced curing time led by the increased curing agent amount, reduced the elasticity and reinforced the brittleness of IPN. So the shear failure types of IPN changed from the interface failure (in Figure 6(b)) to the cohesion failure (in Figure 6(a)).

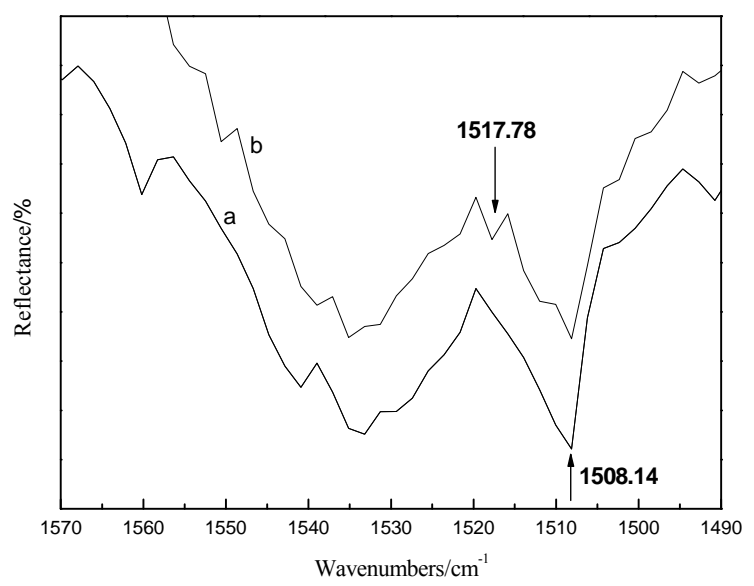

Figure 5. Comparisons of amide II absorption peaks in FTIR spectra of IPN (a) and IPN-Al (b).

Table 2. The shear strengths with different component ratios of prepolymer to curing agent in IPN.

\begin{tabular}{lcccc}
$\begin{array}{l}\text { Curing agent/ } \\
\text { Prepolymer }\end{array}$ & $\begin{array}{c}\text { Shear } \\
\text { strength } / \mathrm{kPa}\end{array}$ & $\begin{array}{c}\text { Average Shear } \\
\text { strength/kPa }\end{array}$ & $\begin{array}{c}\text { Average } \\
\text { deviation }\end{array}$ & $\begin{array}{c}\text { Standard } \\
\text { deviation }\end{array}$ \\
\hline & 343.66 & & & \\
a) $1.628(\mathrm{~mol})$ & 314.08 & 309.09 & 26.38 & 30.473 \\
& 269.52 & & & \\
& 452.72 & & & \\
& 450.10 & 440.14 & 15.02 & 15.969 \\
& 417.61 & & & \\
\end{tabular}




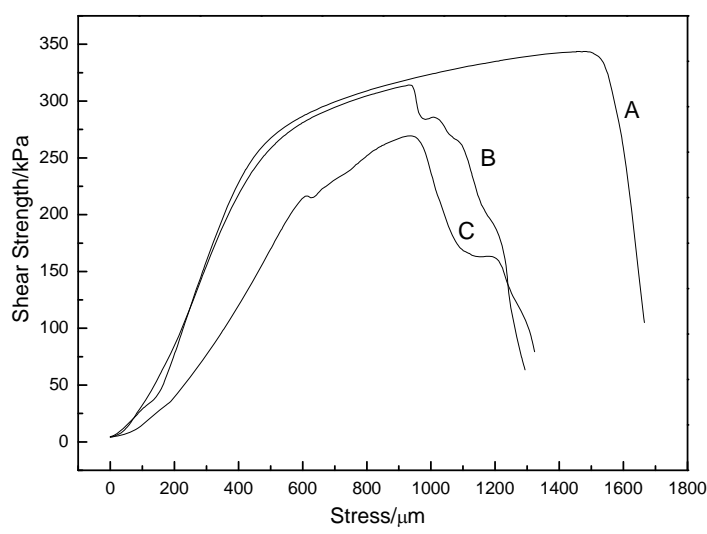

(a)

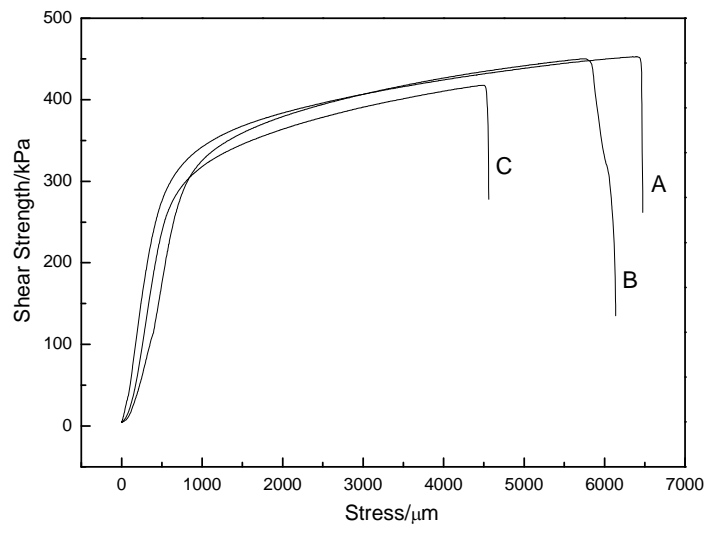

(b)

Figure 6. The shear strength curves of IPN-Al with curing agent to prepolymer(mol) in IPN of (a)-1.628 and (b)-1.385.

\section{Conclusions}

The pretreated porous aluminum increased the surface areas greatly and thus increased the possibilities to form the chemical bonds at interface of the IPN thin film and the aluminum substrate apparently by the intermolecular force and the electrostatic attractions. The higher reactive activities can be achieved at the interface between the nitrogen- and oxygen containing functionalities in IPN and the aluminum. The chemical bond between $-\mathrm{N}=\mathrm{C}=\mathrm{O}$ group and $\mathrm{AlO}(\mathrm{OH})$, and the weak hydrogen bond between the $-\mathrm{N}=\mathrm{C}=\mathrm{O}$ group and the $-\mathrm{OH}$ group (in $\mathrm{AlO}$ $(\mathrm{OH})$ ) can be formed. These interactions reinforced the shear strength apparently, especially when the IPN contained a larger amount of $-\mathrm{N}=\mathrm{C}=\mathrm{O}$ group.

\section{Acknowledgements}

This work was supported by Program for New Century Excellent Talents In Universities (NCET-08-0165).

\section{REFERENCES}

[1] D. H. Kim, K. H. Kim, W. H. Jo and J. Kim, "Studies on
Polymer-Metal Interfaces, 3a An Analysis of Interfacial Characteristics between Aminefunctionalizedpolystyrene/ Copper and between Hydroxyl-Functionalized Polystyrene/Copper," Macromolecular Chemistry and Physics, Vol. 201, No. 18, 2000, pp. 2699-2704. doi:10.1002/1521-3935(20001201)201:18<2699::AID-M ACP2699>3.0.CO;2-M

[2] E. Sabatini, J. C. Boulakia, M. Bruening and I. Rubinstein, "Thioaromatic Monolayers on Gold: A New Family of Self-Assembling Monolayers," Langmuir, Vol. 9, No. 11, 1993, pp. 2974-2981. doi:10.1021/la00035a040

[3] J. F. Watts, A. Rattana and M.-L. Abel, "Interfacial Chemistry of Adhesives on Hydrated Aluminum and HyDrated Aluminum Treated with an Organosilane," Surface and Interface Analysis, Vol. 36, No. 11, 2004, pp. 1449- 1468. doi:10.1002/sia.1918

[4] M. Öhman and D. Persson, "An Integrated in Situ ATR-FTIR and EIS Set-Up to Study Buried MetalPolymer Interfaces Exposed to an Electrolyte Solution," Electrochimica Acta, Vol. 52, No. 16, 2007, pp. 51595171.

[5] M. R. Alexander, S. Payan and T. M. Due, "Interfacial Interactions of Plasma-Polymerized Acrylic Acid and an Oxidized Aluminium Surface Investigated Using XPS, FTIR and Poly(Acrylic Acid) as a Model Compound," Surface and Interface Analysis, Vol. 26, No. 13, 1998, pp. 961-973.

doi:10.1002/(SICI)1096-9918(199812)26:13<961::AID-S IA432>3.0.CO;2-7

[6] G. Y. Seoung, I. Y. Kim, I. K. Sun and S. J. Kim, "Swelling and Electroresponsive Characteristics of InterpeneTrating Polymer Network Hydrogels," Polymer International, Vol. 54, No. 8, 2005, pp. 1169-1174. doi:10.1002/pi.1825

[7] L. J. Atanasoska, S. G. Anderson, H. M.Meyer, Z. Lin and J. H. Weaver, "Aluminum/Polyimide Interface Formation: An X-ray Photoelectron Spectroscopy Study of Selective Chemical Bonding," Journal of Vacuum Science \& Technology A, Vol. 5, No. 6, 1987, pp. 3325-3333. doi:10.1116/1.574191

[8] A. Selmani, "Theoretical Investigation of Chemical Bonding at Aluminum/Polyimide Interface," Journal of Vacuum Science \& Technology A, Vol. 8, No. 1, 1990, pp. 123-126.

[9] A. Calderone, R. Lazzaroni and J. L. Bre'das, "A Theoretical Study of the Interfaces between Aluminum and Poly(Ethylene Terephthalate), Polycaprolactone, and Polystyrene: Illustration of the Reactivity of Aluminum Towards Ester Groups and Phenyl Rings," Macromolecular Theory and Simulations, Vol. 7, No. 5, 1998, pp. 509-520. doi:10.1002/(SICI)1521-3919(19980901)7:5<509::AIDMATS509>3.0.CO;2-Z

[10] J. van den Brand, W. G. Sloof and H. Terryn, "Correlation between Hydroxyl Fraction and O/Al Atomic Ratio as Determined from XPS Spectra of Aluminum Oxide Layers," Surface and Interface Analysis, Vol. 36, No. 1, 2004, pp. 81-88. doi:10.1002/sia.1653

[11] M. R. Alexander, G. Beamson and C. J. Blomfield, "In- 
teraction of Carboxylic Acids with the Oxyhydroxide Surface of Aluminum: Poly(Acrylic Acid), Acetic Acid and Propionic Acid on Pseudoboehmite," Journal of Electron Spectroscopy and Related Phenomena, Vol. 121, No. 1-3, 2001, pp. 19-32.

doi:10.1016/S0368-2048(01)00324-3

[12] H. Hu, J. Saniger, J. Garcia-Alejandre and V. M. Castaño, "Fourier Transform Infrared Spectroscopy Studies of the Reaction between Polyacrylic Acid and Metal Oxides," Materials Letters, Vol. 12, No. 4, 1991, pp. 281-285. doi:10.1016/0167-577X(91)90014-W

[13] J. Yu, M. Ree, Y.H. Park, T.J. Shin, W. Cai, D. Zhou and K.-W. Lee, "Adhesion of Poly(4,4-Oxydiphenylene Pyromellitimide) to Copper Metal Using a Polymeric Primer: Effects of Miscibility and Polyimide Precursor Origin," Macromolecular Chemistry and Physics, Vol. 201, No. 5,
2000, pp. 491-499.

doi:10.1002/(SICI)1521-3935(20000301)201:5<491::AID -MACP491>3.0.CO;2-2

[14] P. G. Roth and F. J. Boerio, "Surface-Enhanced Raman Scattering from Poly(4-Vinyl Pyridine)," Journal of Polymer Science Part B: Polymer Physics, Vol. 25, No. 9, 1987, pp. 1923-1933. doi:10.1002/polb.1987.090250912

[15] W. Possart, C. Bockenheimer and B. Valeske, "The State of Metal Surfaces after Blasting Treatment Part I: Technical Aluminum," Surface and Interface Analysis, Vol. 33, No. 8, 2002, pp. 687-696. doi:10.1002/sia.1436

[16] M. Öhman, D. Persson and C. Leygraf, "In Situ ATRFTIR Studies of the Aluminium/Polymer Interface upon Exposure to Water and Electrolyte," Progress in Organic Coatings, Vol. 57, No. 1, 2006, pp. 78-88. doi:10.1016/j.porgcoat.2006.07.002 